\title{
Cyborgsportpersons: Between Disability and Enhancement
}

Authors' contribution:

A) conception and design of the study

B) acquisition of data

C) analysis and interpretation of data

D) manuscript preparation

E) obtaining funding

\author{
José Luis Pérez Triviño
}

Universitat Pompeu Fabra, Spain

ABSTRACT

\begin{abstract}
The cyborgization of sport has occupied a noticeable role in the fields of sport and medicine in recent years due to the fact that this issue calls into question the very foundations of contemporary sport. As a result, it gives rise to doubt about whether cyborg athletes should be able to take part in different athletic competitions, and if they are allowed, under what circumstances. After examining the impact of enhancing implants and prosthesis in sport, I have considered which objections can be raised to this particular sort of enhancement. In this regard, I think that several aspects have to be taken into account: 1 . The possibility of producing severe harm to the athletes; 2 . The effect it has on equality among athletes when the improvement grants an obvious advantage; 3 . The dehumanization of sport, and 4 . The aesthetic problem My position has been to temper the "moral panic" that some may feel given the progressive (and future) use of enhancing implants and prosthesis as used by (cyborg)athletes.

cyborg, disability, enhancement, sport nature
\end{abstract}

\section{Intruduction}

Recent decades have seen more profound changes to the relationship between human beings and technology: developments in genetics, robotics, cybernetics, nanotechnology, and biomedicine are making it possible to posit that in the future human beings will be able to genetically modify and clone themselves. They will be able to create hybrid beings or interact with computers or other components within the human body itself. In any case, sport is not at the margin of technological enhancement advances to physiological abilities. Sport will not be immune to future changes engendered by technology, no matter how vague or nebulous they may seem to us now. Rather, sport will probably be one of the social spheres where these transformations on the human body will be seen for the first time. Given the idiosyncrasies of athletes, their eagerness to reach new goals, their attraction to fame, their thirst for higher income and the like, it is more likely that they may be the "scouting party" that first experiments with this progress in genetics. Some authors, such as Miah, point out that technological advancements currently applied to sport already make athletes that are posthuman (Miah, 2004).

Technology plays an increasingly important role in sport, not only for those sports in which the athlete uses a type of vehicle (motorcycling, cycling, etc.) and in which technological advances are both continuous and of increasingly greater magnitude. But if the technological advances that are achieved are generally part 
of the accessories used by athletes, they already constitute a problem for purists ${ }^{1}$. Where technology directly affects the human body, the doubts about its legitimacy have already become significant. This has been the challenge to sport ethics in the case of Oscar Pistorius (Zettler, 2009; Marcellini, 2012). But it is probable that in the near future we will see sportspersons wanting to change their organic parts of the body for mechanical prosthesis ${ }^{2}$. As Adelson says: "Next-gen research will shift from replacing the human leg to improving it, just as pharmaceuticals have shifted from restoring to enhancing. Why stop at a better hairline when we can make a better thigh?" 3 They could overcome the able-bodied and become super-abled. But then, why can't an able-bodied change his body technologically to enhance it? This will not be a strange attitude among athletes, as George Dvorsky points out: "Given the 'arms race' nature of competition, will these positional advantages cause athletes to do something as seemingly radical as having their healthy natural limbs replaced by artificial ones?" (Dvorsky, 2007).

The use of technology in sport can be carried out with distinct therapeutic or enhancement goals (Longman, 2007; Miah, 2004). The doubts about its legitimacy in sport arise when it is used for enhancement effects. It is then that this use becomes one of the core matters for sport authorities who must set the conditions regulating athletes' participation in different tests. In the following section, I will examine some of the problems that arise with the use of implants and prosthesis that could lead sportspersons to be cyborgsportpersons. Finally, I will highlight that perhaps there is no reason for the "moral panic" that some scholars forebode.

\section{Cyborgs and sport}

Cyborg is a combination of the words "cybernetic" and "organism"; that is to say, they are organisms made up of biological elements and mechanical, electronic, or robotic devices that are primarily used to better the capabilities of the biological organism through the use of technology.

The term was coined by Manfred E. Clynes and Nathan S. Kline in 1960. Reflecting on this type of creature, they concluded there was a need for a closer link between humans and machines at that historical juncture: point when scientific knowledge and technological development had progressed by leaps and bounds, especially in terms of space exploration.

The cyborgization of sport has occupied a role in the fields of medicine and sports in recent years due to the fact that this issue calls into question the very foundations of contemporary sport. Consequently, it gives rise to doubt about whether cyborg athletes should be able to partake in different athletic competitions, and, if allowed, under what circumstances.

More specifically, this possibility generates inevitable ethical and legal questions. In this sense, the paradox that arises is that medical implants, which were invented with obvious therapeutic and restorative goals, would improve the physical abilities of the (normally disabled) athletes. Yet these enhancements can improve physical performance (Wolbring, 2011; Zettler, 2009). On several occasions, the current state of technical development has led athletes with implants (cyborgs) to achieve better results or times than ablebodied athletes. For this reason, not only do these athletes claim that they should be allowed to take part in

\footnotetext{
${ }^{1}$ There have been other difficult cases: Liz Hartel (postpolio), who won a silver medal in equestrian dressage at the 1952 Olympics. A wheelchair archer, Neroli Fairhall, also competed in the 1984 Olympic Games; however, her disability became an issue as her alleged stability advantage was questioned by traditional upright archers (Marcellini, 2012). A recent case that sparked controversy was PGA Tour, Inc. v Martin, 532 U.S. 661, 683 (2001). It involved a professional golfer who, unable to walk without pain due to a congenital leg disease, sued under the American with Disabilities Act for the right to use a golf cart in professional tournaments (Sandel, 2003, p. 42; Greely, 2004).

2 "It is plausible to think that in 50 years, or maybe less, the 'natural', able-bodied athletes will just appear anachronistic" (Camporesi, 2008, p. 639).

${ }^{3}$ Adelson, Eric "Let 'em play", ESPN Magazine (http://sports.espn.go.com/espnmag/story?id=3357051). Another supporter of this possibility is Hugh Herr, a bilateral amputee, who lost his legs in a climbing accident. Herr wears robotic limbs with motorized ankles and insists he doesn't want his human legs back because soon they'll be archaic. "People have always thought the human body is the ideal", he says. "It's not".
} 
competitions for disabled athletes, but they also claim that they should not be excluded from competitions for normal athletes (Dvorsky, 2007). This is the case of the South African Paralympic athlete Oscar Pistorius, who has reached great notoriety and whose claims have shaken even the most solid foundations of élite sports. His case, as an example of the cyborgization of sport, makes it patently clear that the arguments both for and against the participation of these cyborg athletes in competitions for athletes who are not disabled must be further clarified.

\section{Regulatory problems}

The cases of disabled sportspersons who have been examined highlight some of the problems that sport authorities will have to deal with in the future given that enhancements will produce athletes with better potential physical abilities, leading to the conclusion that modified athletes would have the upper hand when compared to "normal" athletes. What should be done? Should these advantages be considered something similar to doping and then be banned them from participating in competitions, as is now the case? Or rather should they be able to compete head-to-head with normal athletes? Or should specific competitions be created for them only?

Experts in philosophy and ethics in sport have offered a variety of opinions and perspectives on the validity of increased sport performance caused by the increase in mechanical implants in athletes' bodies. Much like objections raised to doping, the reasons informing objections against technological intervention in sport can be categorized into three main areas: 1 . They affect the spirit of the sport, especially the equality among athletes; 2 . They may eventually cause health problems; and 3 . They dehumanize the sport. But to these objections, a fourth must be added: 4 . They represent an aesthetic problem.

\section{The problem of inequality}

This first critique against implants and prosthesis that improve the results in sports is similar to that directed at conventional doping. According to it, physical improvement would be exaggerated in such a way that equality among athletes would no longer exist. But this critique provides a caricature of what the impact of these technologies would be in the playing of sports rather than a description of the actual circumstances. At least in its current state of affairs, technology has not advanced to such an extent that it would be able to create athletes who are vastly superior to "able-bodied" ones. Athletes will have to continue training and making sacrifices to finally achieve good performance in the sports arena. Technology only offers a slight difference to times or goals achieved. Therefore, it follows that the athlete who relies on the miraculous results of a little pill and stops training could hardly be part of the élite.

In fact, in the case of the famous cyborgsportperson Oscar Pistorius, the main argument against his participation in competition is simply that he will obtain illegitimate advantage. But this argument can be refuted, because other scientific studies determined that the cheetah blade offered disadvantages that compensated that presumptive advantage. Effectively, the carbon fiber "legs" generated lower acceleration in the start as well as decreased stability during the race. Another study determined that they conferred a disadvantage regarding the efficiency of the energy, since it only gave back $80 \%$ of the energy absorbed in each step, whereas a natural leg did it in $240 \%$. And finally this data was the main reason to allow him to participate in competitions of able-bodied sportspersons (Edwards, 2008, p. 30; Camporesi, 2008; Zettler, 2009; Marcellini, 2012).

In fact, the equality that would be produced as a result of the generalizing these new treatments would lead to a situation in which effort, dedication, and sacrifice would become more decisive factors in the practice of sports to a greater extent than they are today. Given that athletes would not be as different from each other with regard to their physical abilities, victory in a competition would depend on other factors ${ }^{4}$ : the

\footnotetext{
4 These features may be genetically determined, but they are influenced by an individual's relationship with the environment and by other circumstances linked to the subject's autonomous decision-making abilities.
} 
creative features of the athlete, his excellence of character, his technical decisions, or his ability to take risks. Success in sport would not be left to random circumstances related to an individual's natural genetic lottery or the economic power of the country where the athlete is born. Being born endowed with a certain talent or in a rich country is completely random and it may be possible to find moral reasons for compensating for these undeserved advantages.

These same arguments also serve to confront another criticism against enhancing implants: sport demands continuity with its own history (Caplan, 2008). If technological changes were made in sports clothes (shoes, swimsuit, perches, skis, etc.), then the possibility of comparison between sportspersons (current and past) would be reduced. In the case of the implants, the situation is even worse: it would be doubtful that sportspersons were practicing the same sport (Edwards, 2008). Nonetheless, the answer to this objection consists of pointing out that technological advances have always existed in sport: improvements in the materials of javelins, hockey sticks, bicycles, shoes, and swimsuits. Introduction of diets or even technicians focused on physical recovery has provoked a deep change in sport practice. In this sense, it does not seem that an essential permanent property exists in the sport phenomenon. Sport has been always a changeable phenomenon. Nonetheless, the argument would have a strong impact in a case in which implants and prosthesis enabled one to fly, as a IAFF high authority pointed out to justify the banning of Pistorius: "What will be the next: wing implants?" Or, if the improvement in athletic results were spectacular, beyond the current averages.

The question then becomes what should be done if, in the future, these improvements to physical performance no longer qualify as normal, but rather become transhuman improvements (Tännsjö, 2009). By analyzing the extent of a treatment, it is feasible to distinguish between effects that are therapeutic, enhancement, and transhuman. A therapeutic effect would be one that repairs a body to more or less match its state previous to an illness. An enhancement effect would be one that would allow for an increase in natural human potential within the typical human realm, e.g., increasing an individual's I.Q. from 100 to 104. A transhuman effect would be superhuman improvement, that is, the increase of a person's abilities beyond the characteristic scope of the human species, e.g., increasing an individual's I.Q. from 100 to 200.

In this last case, it would seem reasonable to establish segregated competitions. In the same way there is justification for setting up segregated competitions based on age, weight, or sex (King, 2011). More than enough reasons could be given to create competitions for those individuals that have superhuman physical abilities. It is obvious that we are unaware of the possible effects that these competitions could have on traditional favorites. Would they catch the attention of sports' traditional fan base, or would they remain in the background? In any case, there is no reason to impede the establishment of tests and competitions for these new athletes.

\section{The problem of protection of health}

Regarding this second objection, that technology could affect health, it has been pointed out that technology has not yet reached a point in development where it would produce consequences that are detrimental to health. In this way, it is suggested that cyborg sports with their improved technology would put the security and health of an athlete at grave risk due to the lack of knowledge of the long-term consequences of modifications to the human body. In effect, artificial implants in the human body may produce unpredictable consequences. In effect, in some cases long-term and chronic damage has been detected.

The problem with this objection is that it is an unjustified paternalistic argument. The harm argument implies that the State has to interfere in the will of a rational and autonomous athlete limiting his free decision sphere.

The classic antipaternalistic objection establishes that the only legitimate reason that the State has to coercively interfere in the free sphere of individuals is to avoid harm to others. Thus, the appeal to individual well-being does not in itself constitute a good reason to coercively limit their autonomy in the decision. If we 
apply this argument to athletes, their freedom to have a prosthesis should not be limited, even when this decision may entail certain risks to their health. Other authors point out that the only exception is when these risks are excessive. It seems reasonable to accept that the principle of caution can apply in cases in which the prostheses and implants present important risks or when the necessary controls of quality and experimentation have not happened. But not for the rest of the cases.

Regarding the harm to others argument, the concern for the protection of the health and the physical integrity of other athletes was mentioned in the case of Pistorius. It implies that the cheetah blade could, in the case of a fall, produce damage to other athletes. However, those that supported this objection would have to be coherent and forbid Pistorius from running in the competitions for disabled, where obviously there was the same risk. On the other hand, it seems evident that not all the prostheses and implants are dangerous for other athletes.

It follows that, save in cases where third-party interests are at stake or where there is incomplete knowledge on the effects of medical and scientific treatment to an athlete's body, I believe it is opportune to respect the autonomy of the individual even when he decides to undergo an intervention to improve his sport performance. Despite the fact that an athlete may be running the risk of negatively affecting his health, the athlete - just as any other autonomous citizen - is capable of deciding his own life plan, even if this implies a health risk. A ban would be an example of unjustified paternalism.

\section{The problem of dehumanization of sport}

The third objection deals with ethical matters: the "dehumanization" of sport (Sandel, 2003), given that it reduces the scope of an element that has been considered part and parcel of fair competition. As Simon points out, athletes' extensive use of physical performance enhancement techniques may lead to a situation in which "we are incapable of identifying the original 'I' whose performance we want to improve" (Schneider, 2000). Others authors believe that the purity of sport is in danger: "the athlete with a device can be considered a significant personification of the loss of meaning in the sports spectacle" (Marcellini, 2012).

There are several objections to the use of genetic technology, and particularly to its use in sport, but the principle objection is one that implies that our humanity is threatened. The problem here is with the characterization of "humanity" (Culbertson, 2007; Savulescu, 2007; Schneider, 2009). On some occasions, human beings as moral agents have been identified by belonging to the human species; on others, by their ability to feel. But perhaps currently the most widespread conception of "humanity" resides in the possession of superior cognitive abilities such as rationality, autonomy, consciousness, and self-consciousness. If this conception is adopted, it does not in any way seem that technologically modified athletes (at least to a certain point) lose their humanity: they reflect and feel, they are self-conscious, and they can establish future life plans.

One variant of this criticism comes from Michael Sandel, who expresses the fear that human beings are playing God and are going against Nature (Sandel, 2003). Leaving aside the religious interpretation, in which the concern is that humans literally usurp the role of a superior being, we will center our analysis on the secular interpretation: the main concern that humans may not recognize their own limitations. To put it another way, they express "hubris," an exaggerated self-pride in their abilities as natural beings.

But the answer to this fear is that

The history of humanity has always consisted of modifying the world for good reasons. The natural state of man would be 'disagreeable, brutal and short' to use Hobbes' words if it were not for the many improvements obtained by modifying the world. Vaccines, antibiotics and practically all medicine entail powerful interventions. The objection that we would be playing God is only valid as a precaution against ill-informed actions, to which humans are undoubtedly predisposed (Savulescu, 2007). 
For authors who declare that they are in favor of a "pure" sport, the appearance of cyborgs, in any of their manifestations whether lighter or more extreme, calls into question the ideal of bodily purity that must govern the practice of sports ${ }^{5}$. From here, the fear is that sport will collapse due to the collective inability to recognize "pure" athletes, especially when we consider that many non-athletes are profoundly "cyborgized" though artificial organs and parts, as well as through distinct types of medication ${ }^{6}$.

On the other hand, experts in favor of the use of new technologies in sport question the arbitrary and binary methods that are at times used to define what constitutes a human being (Butryn, 2003). Nevertheless, they do deny that technological advances necessarily dehumanize the practice of sport. Along these lines, they highlight that all individuals (and consequently all athletes, too) exercise freedom to question the limits imposed by nature, "to challenge the projected limited of modern sport, including those dealing with humans, machines and technology, and to explore new ways of being 'cyborg' though the interaction with technologies at our disposal" (Bostrom, 2003). The continual efforts carried out by sport bureaucracy have also been denounced, as they forcibly impose a rigid separation between "natural" and "technological" competitors.

Another strategy to demonstrate the inefficiency of excluding technologically modified athletes stems from highlighting the contradiction that this involves when compared to the current situation in which athletes have undergone therapeutic treatments that were unimaginable a number of years ago and without which they would not achieved their actual level success. In this way, for example, Messi - the now famous footballer - took growth hormones as an adolescent and Tiger Woods had eye surgery to overcome problems with short-sightedness. It is clear that these are cases of therapeutic treatments, but perhaps it will have to be considered that 1 . There are already enhancement treatments (like vaccines); 2 . As long as it is possible in the future that these initially-therapeutic treatments allow the patient to improve on his previous abilities, or to broaden the spectrum of the human average, we will be on slippery ground. This boundary between therapeutic and enhancement treatments may become fuzzy. No one criterion exists to denote what is considered a "disease", and, consequently, no limiting criterion is known for "therapies", either. For example, Borse offers a biological-determinist conception of disease, while Daniels advocates a socialconstructivist focus. Depending on which criteria are adopted, (therapeutic) treatments can be more or less widespread. In other words, the scope of therapy could increase and, in this way, diffuse what an enhancement treatment would be (Miah, 2004).

The sports practiced by athletes who have had organs or mechanical parts implanted and their desire to take part in regular athletic competitions put sports authorities in an ethical and legal tight spot. For example, an athlete who plays American football must be somewhat heavy to be able to successfully carry out his mission on the field, but this means reducing his life expectancy by an average of 25 years. Even if these negative health consequences, which improve athletic performance, are borne out, the player is not barred from playing. An athlete who undergoes a "Tommy John"7 operation could even play as pitcher for a baseball team. Nevertheless, another athlete who wants to replace his arm or his leg for an artificial one that would improve his scores in the field or allow him to play better would not be allowed to do so under current legislation. But what is the ethical difference between the two treatments? Take another example that could

\footnotetext{
${ }^{5}$ But as Zettler has pointed out: "sports themselves are arguably 'unnatural' ... the distinction between natural and unnatural is a weak basis on which to determine whether athletes and equipment are eligible for competition" (Zettler, 2009, p. 400).

6 "From an identity standpoint, what does it mean to have a disability? Pamela Anderson has more prosthetic in her body than I do. Nobody calls her disabled". Aimée Mullins, double amputee athlete (http://www.ted.com/talks/aimee_ mullins_prosthetic_aesthetics.html. Last visited: 10/1/2013).

7 "Tommy John surgery" is the media's name for the medical practice as ulnar collateral ligament (UCL) reconstruction of the elbow. It was in 1974 that Dr. Frank Jobe carried out an experiment on Tommy John, a pitcher for the Dodgers baseball team. Jobe extracted a tendon from John's right arm and used it to replace a severed one in the left arm. It was put into place with pins that opened in the bone above and below the elbow. The player was not only able to return to playing baseball, but he also won 170 more games in his career. In other words, his performance remarkably improved after the operation. See: http:/caibco.ucv.ve/caibco/vitae/VitaeOnce/Articulos/Traumatologia/paginashtml/ Traumatologia.pdf).
} 
be perplexing if bans on devices that improve sport performance were banned ("any technical device that uses springs, wheels or any other element that provides the user with an advantage over other athletes who do not use such device"). According to this ban, it would be prohibited for a golfer to use contact lenses to correct short-sightedness, but it would not be forbidden that he play after having surgery to correct the condition. This is the case of Tiger Woods. It would be very strange and paradoxical that an individual were kept from playing if he wore contacts, but he would be allowed to play if he had undergone surgery when the results for all practical purposes would be the same ${ }^{8}$.

\section{The aesthetic problem}

In the fourth and final position is the problem with aesthetics, an objection of much shallower depth in theoretical and ethical terms. According to one response to this problem, the idea undergirding this critique is that spectators would have difficulty accepting sport competitions with "normal" athletes and those with atypical morphology, that is to say, with cyborg athletes. Such difficulties could be based on feelings of aesthetic displeasure upon observing athletes with implants on the human body or simply because of inertia, i.e., it is difficult to get used to seeing a new kind of show (Zettler, 2009, p. 396).

In any case, this objection would not greatly affect the participation of those athletes in competition with normal athletes or in segregated competition; rather, it is directed at the fans' potential response. In other words, would spectators be willing to pay for tickets to see modified athletes in a stadium setting? Besides this question, there is another, previous problem to be addressed: the definition of what could be taken as atypical morphology. If what is taken as a point of reference is a significant variation compared to an established statistical norm, then exclusion could be extended to those athletes who are extremely tall or short. Titles or medals could even be revoked for those athletes with some type of physical anomaly that gave them an advantage over their rivals, as were the cases of Eero Mantyranta and Miguel Induráin. In addition, there are internal and external implants and prostheses. Why should the former be allowed and not the latter? Along these lines, an interesting case is the one of cyclist Floyd Landis who suffered a hip injury in 2003, resulting in a prosthetic hip in 2006. Curiously, this did not generate problems, even though the artificial hip could be clearly seen (van Hilvoorde-Laurens, 2008, p. 22).

The second version of this critique is more powerful, as it calls attention to the fact that a distinction must be drawn between the modification and the replacement of an organ. Following this line of reasoning, the surgical modification of a muscle, or even the modification of a cornea through laser surgery, would not be equal to implanting carbon fibers to replace biological legs.

This argument may fail under the first critique due to the fact that one type of technology is "not the same" as another. This argument has repercussions for the physical or external aspects of the athlete. If this were the meaning of the critique, the response is the same: it does not seem justifiable to exclude athletes with implants for aesthetic reasons. It is the athlete's ability that is important, not the physical appearance.

For, as well as overcoming considerable levels of prejudice and disadvantage due to his disability, Oscar Pistorius is as dedicated and trains as hard as any top athlete. The blades are mere means that make it possible for him to manifest his athletic prowess in his chosen events; they compensate for his lack of legs. (Edwards, 2008, 29)

Yet "it is not the same" can have another meaning: the technology that replaces the organ in a body can have enhancement effects that are much greater than simple modification technologies may have. Two responses can be given with regard to this objection. It is not always the case that there is a direct or causal link between "replacement-greater performance" and "modification-decreased performance." For example,

\footnotetext{
${ }^{8}$ Adelson points out another hard case: "USA Track \& Field has worked with Nike to test carbon-sole shoe implants that harness energy normally lost when a runner's foot pushes off. Americans wore the shoes in the Sydney Olympics, meaning able-bodied sprinters have already used the type of carbon-infused prosthetics that got Pistorius banned. What's the difference between carbon shoes and carbon tibiae? Fashion?" (Adelson).
} 
in the future, genetic interventions will likely produce substantial physiological improvements without simultaneously modifying the external appearance of the athlete. In addition, in Paralympic trials, there are athletes with replacement prosthetics who hardly demonstrate any physical improvements, or, in any case, they are not comparable to the developments of "trained" athletes.

Yet another aspect to consider is that even if this link did exist, then the argument to establish regulatory changes to competition so that athletes could participate (or not) would impact performance in sport. Consequently, the eventual inequality would be seen regardless of the type of technology that was produced or what the external physical appearance of the athlete looked like.

\section{Conclusions}

After examining the impact of enhancing implants and prosthesis in sport, I have considered which objections can be raised to this particular sort of enhancement. In this respect, I think that several aspects have to be taken into account: 1 . The possibility to produce severe harm to the athletes; 2 . The effect it has on equality among athletes when the improvement grants an obvious advantage; 3 ) The dehumanization of sport, and 4 . The aesthetic problem.

Regarding the first point, it is necessary to examine cases which would justify the eventual prohibition of enhancement treatments: 1 . When there is harm to others; 2 . When there is insufficient knowledge about the effects it would have on health. However, in the case in which the health risk falls upon the athlete himself, the rest of the arguments that are used or that will be used to limit the participation of these new athletes are clearly part and parcel of unjustified paternalism.

Regarding the second argument, it is necessary to distinguish between two possible effects of technological intervention: whether the improvement of physical ability is strictly "enhancing" or if it is "transhuman" in nature.

In terms of this distinction, which would require a degree of precision impossible to carry out in the scope of this paper, if the interventions on the athlete are enhancements, the nature of the sport itself would not be violated. Therefore, moral reasons cannot be given to prohibit said treatments. Of course, to be able to accept such treatments, another condition is necessary: that equality of opportunity exists among athletes regarding access to improvements.

However, if the interventions are transhuman in nature, it seems obvious that sport would be substantially altered. The possibility that athletes with transhuman physical enhancements could compete on the same playing field with untreated athletes would affect equality among athletes, and in this way it would completely remove virtue from the results and take away the excitement of the game.

Notwithstanding, the solution does not necessarily lie in banning such modifications; rather, it may eventually seem reasonable for transhuman athletes to establish separate competitions.

Regarding the third objection, which focuses on the dehumanization of sport, my point has been to underline that the definition of "humanity" is a far from a specific one, and that, in any case, if humanity is understood as a set of cognitive abilities that allow the human agent to shape his future, then these enhancement techniques do not necessarily limit or eradicate these functions. This is so, as athletes exercise their autonomy when they decide to opt for these treatments. In addition, I have shown a lack of coherence in the argument for banning certain enhancement measures that are allowed in other areas of social life and within sports themselves.

Lastly, the aesthetic problem can be seen a perfectionist argument which has its core in a certain prejudice seen in the aesthetic preferences of the majority. From another point of view the argument is about the definition of what could be taken as atypical morphology. But this a vague claim and besides, in current sport, there are already many different kinds of physical anomalies. On the other hand, I have examined the distinction between the modification and the replacement of an organ, concluding that such a distinction is not conclusive enough. 
In short, my position has been to temper the "moral panic" that some may feel given the progressive (and future) use of enhancing implants and prosthesis as used by (cyborg)athletes.

\section{REFERENCES}

Adelson, E. (2011)."Let 'em play", ESPN Magazine. Retrieved 25.02.2013 from http://sports.espn.go.com/ espnmag/story?id=3357051).

Bostrom, N. (2003). Human Genetic Enhancements: A transhumanist Perspective. Journal of Value Inquiry, 37(4), 493506.

Butryn, T.D. (2003). Posthuman Podiums: Cyborg Narrative of Elite Track and Field Athletes. Sociology of Sport Journal, 20, 17-39.

Camporesi, S. (2008). Oscar Pistorius, enhancement and post-humans. Journal of Medical Ethics, 34(9), 639.

Caplan, A. (2008). Blade Runner' Ruling Subverts Nature of Sport: Artificial Legs Would Make for Artificial Competition at Beijing Olympics, MSNBC.com, May 22, 2008, Retrieved from http://www.msnbc.msn.com/id/ 24758518/

Culbertson, L. (2007). "Human-ness", “dehumanisation” and performance enhancement. Sport, Ethics and Philosophy, $1(2), 195-217$.

Dvorsky G. (2007). Is the world ready for cyborg athletes? 25 April 2007. Retrieved 14.07.2008 from http://ieet.org/ index.php/IEET/more/dvorsky20070425.

Edwards, S.D. (2008). Should Oscar Pistorius Be Excluded From the 2008 Olympic Games? Sports Ethics and Philosophy, 2(2), 112-125.

Fukuyama, F. (2002). Our Posthuman Future: Consequences of the Biotechnologicaly Revolution. London: Profile Books.

Greely, H. T. (2004). Disabilities, Enhancements, and the Meanings of Sports. Stan L \& Pol'y Rev, 15, 99-155.

Hoberman, J. (1992). Mortal Engines. The Science of Performance and the Dehumanization of Sport. New York: The Free Press.

King, M. (2011). A league of their own? Evaluating justifications for the division of sport into "enhanced" and "unenhanced" leagues. Sport Ethics and Philosophy, 5(4), 31-45.

Longman, J. (2007). An amputee sprinter: is he disabled or too-abled? The New York Times, 15 May.

McNamee, M., Edwards, S.D. (2006). Medical Technology and Slippery Slopes. Journal of Medical Ethics, 32(9), 513518.

Marcellini, A., Ferez, S., Issanchou, D., De Léséleuc, E., McNamee, M. (2012). Challenging human and sporting boundaries: The case of Oscar Pistorius. Performance Enhancement \& Health, 1(1), 3-9. DOI: 10.1016/j.peh. 2011.11.002.

Miah, A. (2004). Genetically modified athletes. London-New York: E\&FN Spon (Routledge).

Sandel, M. (2003). The Case Against Perfectionism. Cambridge: The Belknap Press of Harvard University Press.

Savulescu, J. (2007). Gene therapy, transgenesis and chimeras: is the radical genetic alteration of human beings a threat to our humanity? In J. Savulescu (Ed.), Quest of Ethical Wisdom: How the Practical Ethics of East and West Contribute to Wisdom (pp. 3-20). Oxford: Oxford Uehiro Centre for Practical Ethics.

Savulescu, J., Foddy, B., Clayton, M. (2004). Why We Should Allow Performance Enhancing Drugs in Sport. British journal of sports medicine, 38, 666-670.

Schneider, A., Rupert, J. (2009). Constructing Winners: The Science and Ethics of Genetically Manipulating Athletes. Journal of Philosophy of Sport, 36(2), 182-206.

Schneider, A. (2000). On the definition of 'woman' in the sport context. In T. Tännsjö \& C.M. Tamburrini (Eds.), Values in Sport. Elitism, nationalism, gender equality and the scientific manufacturing of winners (pp. 123-138). London-New York: E\&FN Spon (Routledge).

Simon, R. (1993). Fair Play. Sports, values and society. Boulder: Westview Press.

Tamburrini, C.M. (2000). ¿La mano de Dios? Una visión distinta del deporte /The 'Hand of God'. Essays in the Philosophy of Sports/. Buenos Aires: Continente.

Tamburrini, C.M. (2011). What's Wrong With JS Mill's “Harm-to-Others" Principle? Journal of the Philosophy of Sport, 38(1), 1-26.

Tännsjö, T. (2009). Medical Enhancement and the Ethos od Elite Sport. In J. Savulescu, N. Bostrom (Eds.), Human Enhancement. Oxford: Oxford University Press. 
Tännsjö, T., Tamburrini, C.M. (2006). Las bioamazonas del fútbol /The bioamazons of football/. In C. Torres \& D. Campos ¿La pelota no dobla? Ensayos filosóficos en torno al fútbol /¿The ball does not bend? Philosophical Essays about Football/ (pp. 187-210). Buenos Aires: Zorzal.

van Hilvoorde, I., Landeweerd, L. (2008). Disability or Extraordinary Talent - Francesco Lentini (Three Legs) Versus Oscar Pistorius (No Legs). Sport, Ethics and Philosophy, 2, 97-111.

Wolbring, G. (2011). Hearing Beyond the Normal Enabled by Therapeutic Devices: The Role of the Recipient and the Hearing Profession. Neuroethics, June, 1-10. DOI:10.1007/s12152-011-9120-x.

Wolbring, G. (2011). Who will be the future Olympic and Paralympic Athlete Subtitle Advances in Science and Technology, bodily assistive devices and the future face and purpose of Sport. Retrieved 02.10.2011 from http://www.bioethicsanddisability.org/vancouverpodcast.html

Zettler, P.J. (2009). Is it Cheating to use cheetahs?: The implications of Technologically innovative prostheses for Sports values and rules. Boston University International Law Journal, 27, 308-409.

AUTHOR'S ADDRESS: $\quad$ José Luis Pérez Triviño Departamento de Derecho Despacho 0E20. Edificio Roger de Llúria Trías Fargas, 25-27

08005 Barcelona

Spain

Email: jose.perez@upf.edu 